\title{
Explain This!
}

\author{
Deb Gauldin, RN, PMS
}

\begin{abstract}
Childbirth educator humorously discusses props used as tools for teaching and teasing.
\end{abstract}

Journal of Perinatal Education, 14(2), 59-60, doi: 10.1624/105812405X44763

Keywords: humor, childbirth education

When it comes to caring, no one beats a childbirth educator. When it comes to carrying, the same is true. The props, posters, and paraphernalia childbirth educators cram into tote bags and schlep from class to class could easily bring a Sherpa and his yak to tears.

Many an awkward fourth grader has gingerly stepped over a renegade breast model or graphic poster in order to take a seat in my carpool. I suspect most childbirth educators' families are completely desensitized to the image of a crowning vulva or plugged milk duct. They can eat a bowl of cereal even if, next to them at the kitchen table, sits a "Cabbage Patch" pelvis. No explanation needed.

It was a natural leap for me to use props as part of my comedy presentations. In fact, I now ship these items to various engagements rather than face the embarrassment of yet another airport security agent pulling me aside to pass a detection wand over my padded placenta. And just as an FYI: Commenting that "it's merely afterbirth" does not speed up the process or result in sympathy from the passengers still waiting in line behind me. But I digress!

One gag I use in my comedy routines is a favorite. It requires holding up a very large $\operatorname{Kotex}^{\circledR}$ to which gold lamé wings have been sewn. The golden wings beg the following consideration: "After all we go through as women, aren't these the wings we really deserve?" Pondering this idea results in much laughter, but removing the adhesive backing and applying what looks like a super-absorbent "maxi-angel" to my lapel is even more absurd. "Angel pins are so popular," I throw out to the audience as I reach for a glass of water. Of course, the real roar comes when I use the end of the peri-pad fashion accessory to dab away a dribble from the corner of my mouth. Okay, so it amuses me.

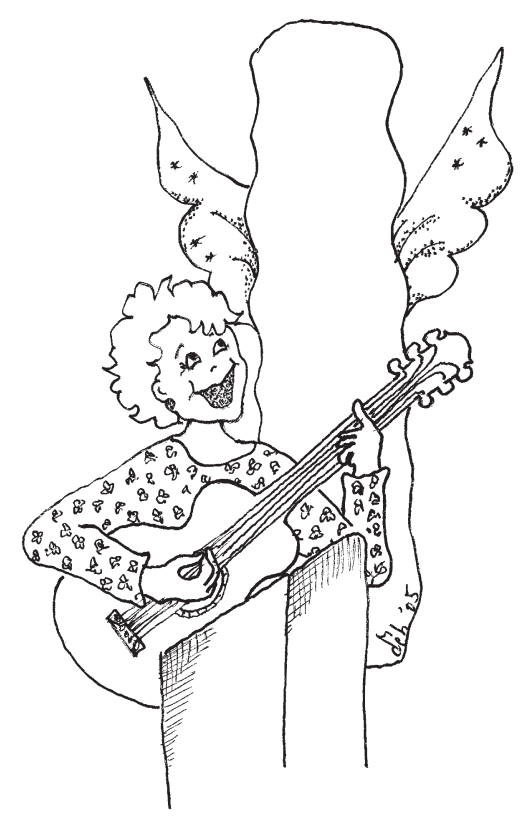


Payback for such silliness came during a recent program. Giving the group sufficient time to recover from the angel bit, I placed the Kotex ${ }^{\circledR}$ to the side of the podium and continued my performance. Chuckles and giggles began building into knee slaps and guffaws, but I was clueless as to the trigger. Uncomfortable, my eyes darted from side to side and then glanced behind me. The surface where I had inadvertently placed the Kotex ${ }^{\circledR}$ was projecting the image onto the entire wall. Looming over me and spanning the huge conference room was a 12-story high sanitary napkin with wings.

It was hysterical then, but not so funny when, 24 hours later, a relative brought the front page of their local paper to my husband's family reunion. My in-laws were surprised to see my picture in the newspaper. But, like you, they were not the least surprised to see what I had carried along with me that day. I didn't even attempt to explain.

DEB GAULDIN is a childbirth educator who travels nationally presenting keynotes and workshops. For booking information, call 800-682-2347 or visit her Web site (www.debgauldin.com). Deb's CDs and tapes contain humor and songs about pregnancy, childbirth, and the adjustment to parenthood. They are available through Lamaze International (800-368-4404).

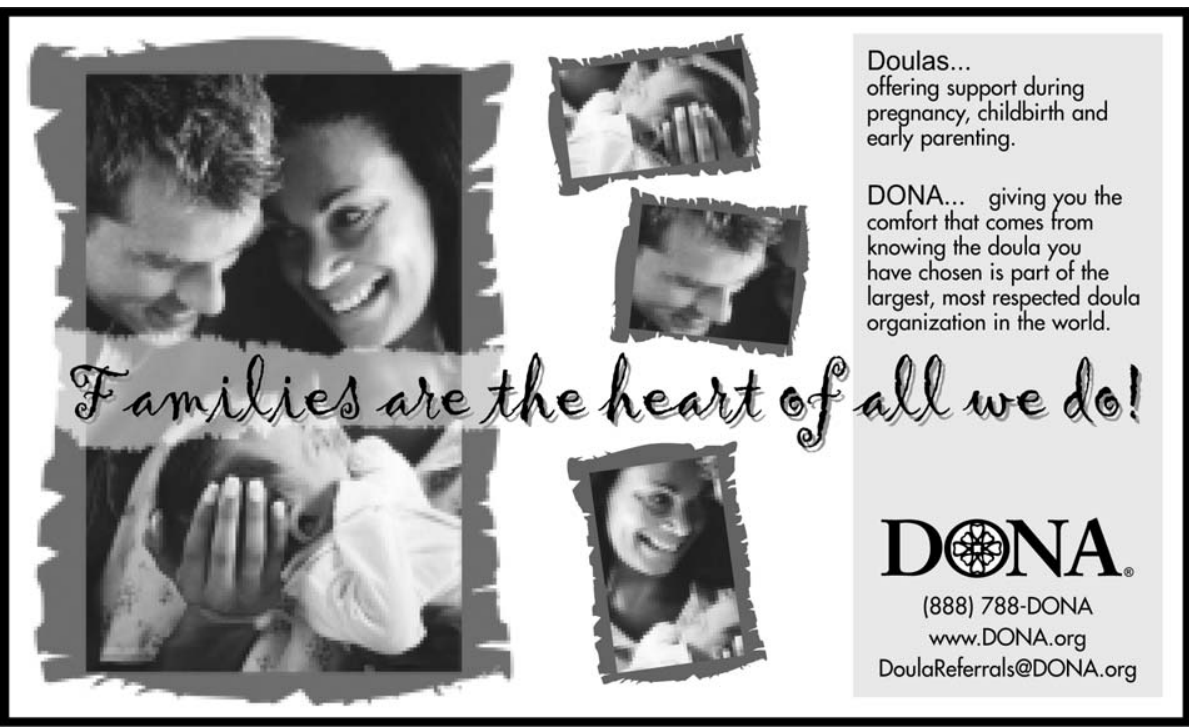

